\title{
Social role patterning in early adulthood in the USA: adolescent predictors and concurrent wellbeing across four distinct configurations
}

\author{
Jennifer L. Maggs \\ The Pennsylvania State University, University of Michigan \\ jmaggs@psu.edu \\ Justin Jager \\ Eunice Kennedy Shriver National Institute of Child Health and Human Development \\ Megan E. Patrick, John Schulenberg \\ University of Michigan
}

\section{Abstract}

The decade following secondary school is pivotal in setting the stage for adulthood functioning and adjustment. We identify four social role configurations of early adults in their mid-20s using latent class analyses in two nationally representative samples of American youth in their last year of secondary education (modal age 18) who were followed longitudinally into adulthood (age 25/26). We focus on the big five social role domains of early adulthood: education, residential status, employment, cohabitation/marriage, and parenthood. Aims were to identify latent classes of social role configurations in early adulthood, examine demographic and late adolescent educational predictors of these classes, and explore contemporaneous health and adjustment correlates focusing on life satisfaction, economic independence, and substance use. Four classes with very similar characteristics and prevalence were identified in the two cohorts who were born 12 years apart: Educated Students without Children (8\% in 80 s cohort/9\% in 90s cohort); Working Singles Living with Parents (16\%/18\%); Educated Workers without Children (45\%/46\%); and Married Workers with Children (31\%/27\%). Late adolescent demographic and educational variables and mid20 s variables were related to class membership. Results evidenced notable similarities (and some differences) across cohorts. Discussion focuses on how roles facilitate or inhibit each other and the potential diversity of optimal patterns of transitions to adulthood.

\section{Introduction}

The decade following high school is pivotal in setting the stage for adulthood functioning and adjustment. In descriptions of the nature of the transition to adulthood in contemporary Western societies, psychological models tend to emphasize self-directed exploration (e.g. Arnett 2000), demographic traditions highlight the impact of social structure on the life course (e.g. Fussell and
Furstenberg 2005), and interdisciplinary approaches focus on the interaction of historical, cultural, and structural constraints with personal agency in the creation of individualized life courses (e.g. Beck 1992; Bynner 2005; Côté and Bynner 2008; Schulenberg et al 2003; Schulenberg and Zarrett 2006; Settersten 2007a, 2009; Settersten et al 2005; Shanahan 2000).

Despite some differences, dominant models of 
the decade following the completion of mandatory education share three important areas of agreement. First, it is broadly agreed that the last 50 years have heralded (a) later median ages at the initiation of traditional adult roles (Amato et al 2007; Arnett 2000; Bynner 2005; Settersten 2007); (b) greater withinand between-country heterogeneity in the timing, order, and resulting patterns at any given point in time (Bell et al 2007; Bynner 2005; Cook and Furstenberg 2002; Cooksey and Rindfuss 2001; Fussell and Furstenberg 2005; Schulenberg et al 2003); and (c) increased individualization of the life course, resulting in more choices and a correspondingly greater need for personal agency and soft skills such as teamwork and networking (Beck 1992; Bynner 2005; Cook and Furstenberg 2002). Second, dominant models note that formal social institutions and informal social norms provide less structure after the end of secondary school, with individuals able to take on a diverse set of potential life changes, including school completion, employment, residential independence, intimate cohabitation or marriage, and parenthood (Cook and Furstenberg 2002; Fussell and Furstenberg 2005; Schulenberg and Zarrett 2006; Settersten 2007). Third, scholars agree that the $20 \mathrm{~s}$ are dense with transitions to adult work and family roles, and are pivotal for developing healthy and fulfilling lifestyles (Schulenberg et al 2003; Settersten et al 2005; Shanahan 2000). As a result, Settersten (2007) concluded that this decade is both formative and risk-laden, a period that contributes to the accumulation of advantage and disadvantage over the life course (Côté and Bynner 2008; Dannefer 2003; Danziger and Rouse 2007).

In this paper, we focus on role configurations of early adults in their mid-20s. We explore the heterogeneity of social roles and how these are combined in the lives of participants in two nationally representative samples of American youth in their last year of secondary education, who were followed longitudinally into adulthood. Data are drawn from the ongoing Monitoring the Future study, focusing here on two cohorts who graduated from high school 12 years apart. We focus on the big five social role domains of early adulthood (Settersten 2007): education, residential status, employment, cohabitation/marriage, and parenthood. We focus on ages 25 to 26 because most young adults have completed formal education by this point, freeing them from the constraints that the pursuit of formal education places on marriage, parenthood, and employment, because considerable heterogeneity in configurations of roles is both possible and likely (Cooksey and Rindfuss 2001), and because this age focus facilitates comparability with three related studies (Räikkönen et al 2012; Salmela-Aro et al 2012; Schoon et al 2012). Our three aims are to: (1) identify heterogeneity in social role configuration during early adulthood using latent class analysis; (2) examine whether demographic and educational aspirations and performance assessed during the senior year of high school (modal age 18) predict social role configurations at ages 25/26; and (3) examine concurrent health and adjustment correlates of the configurations, including substance use, economic independence, and life satisfaction. The introduction focuses on the background to each of the three aims in turn.

\section{Role patterns in young adulthood (Aim 1)}

What is known about prototypic role configurations for young adults? Osgood and colleagues (2005) classified young adults in a longitudinal study of a regional sample of white working- and middle-class youth, based on their role involvement in five adult social roles at age 24 (in approximately 1996), identifying six paths to adulthood. "Fast starters" tended to be partners, parents, living independently, and in long-term employment, with a low likelihood of having completed a college degree. "Parents without careers" had similar spousal and parental roles as well as independence from their own parents and low education, but differed from Fast starters primarily by having lower levels of employment. "Educated partners" lived with partners rather than parents, but had not become parents themselves. They tended to be employed and to have higher levels of education. "Educated singles" (the largest group at 37\%) did not live with romantic partners, but rather with parents or in rented housing. They had the highest levels of education. "Working singles" were not yet parents or partners, and tended to live with parents and be employed full-time. Their typical level of education was to have attained some college, but not a degree. Finally, "Slow starters" tended to have made the 
fewest transitions, live at home, not be partnered, have low education, and be unemployed or in shortterm jobs. Thirty percent of this group were parents, compared to $20 \%$ in the full sample. Osgood et al (2005) provide an important foundation for the present analyses due to its person-centered approach, identification of cohesive role-based configurations in early adulthood, and examination of correlates of role combinations. In Aim 1, we seek to extend their analyses in a longitudinal communitybased sample by using similar indicators of social roles with the addition of current student status, employing a nationally representative US sample of high school seniors followed longitudinally, examining contemporaneous correlates in the mid-20s, and replicating results among young adults in similar (1990s) and earlier (1980s) historical time periods.

\section{Predictors of young adult role patterns (Aim 2)}

Who is likely to inhabit specific configurations of social roles in young adulthood? Past research suggests the key importance of education in shaping the timing and sequence of adult role transitions (Sandefur et al 2005). Specifically, those who pursue higher education tend to initiate the adult roles of partner, parent, and employee later; during this time many receive significant assistance in the form of parental financial support and subsidies (Schoeni and Ross 2005). Education tends to confer significantly higher incomes (DeNavasWalt et al 2010; Goldin and Katz 2007), and has arguably become more important historically as careers have become less secure and more variable and self-directed (Beck 1992; Settersten 2007). In this way, the more educated group may receive multiple benefits not experienced by all. Of course, opportunities to pursue higher education are, in turn, not randomly distributed in the population (Dannefer 2003). Due to the importance of education in shaping the transition to adulthood (Sandefur et al 2005), we focused on educational as well as demographic predictors, assessed at age 18 , of age 25/26 role configurations. Specifically, for aim 2, we focus on two types of predictors: sociodemographics (gender, race/ethnicity, two-parent family, parent education) and educational background (high school academic performance, aspirations to attend college, aspirations to attend trade school). We ask the research question: to what extent do socio-demographic and educational background indicators assessed at the end of high school predict the role configurations participants inhabit at ages 25 to 26 ?

\section{Wellbeing correlates of role patterns (Aim 3)}

There are several concerns regarding how wellbeing relates to the role patterns. For example, is one role configuration ideally conducive to health and wellbeing? Or, do different configurations coincide with complex patterns of risk and benefits? We focus on three domains of wellbeing in young adulthood: life satisfaction, economic independence, and substance use. The mid-20s are a period of normative developmental changes toward greater health and independence. For example, subjective markers of adjustment and life satisfaction increase (Galambos et al 2006; Schulenberg et al 2004) as does economic independence (Bell et al 2007). On average, harmful substance use declines (Johnston et al 2011b), particularly among those who are presently partnered (Bachman et al 1997; Staff et al 2010; Staff et al 2012). Although the normative pattern is toward increased healthy lifestyles and greater wellbeing, this is not true for all. In the US, the third decade of life is when many substance use disorders and psychopathology manifest, unemployment is high, and access to health insurance is the lowest in the lifespan (Danziger and Rouse 2007; DeNavas-Walt et al 2010; Levy 2007; Osgood et al 2006; Settersten et al 2005; Zucker et al 1995). Historic declines in the availability of living wages and affordable housing have added to the challenges of launching adult independence. Thus, even though wellbeing tends to increase, so do serious difficulties highlighting the increased heterogeneity or "fanning" of individual differences during the third decade of life (Schulenberg and Zarrett 2006).

Recent depictions of the transition to adulthood and the young adult period have highlighted both the increased importance of exploration of roles before settling on permanent decisions (Arnett 2000) and the significant challenges faced in recent decades of negotiating the transition to adult roles (Danziger and Rouse 2007; Settersten et al 2005). In the present study, we examine whether indicators of contemporaneous wellbeing-such as substance use, economic independence, and life satisfaction-differ 
among our observed role configurations. By doing so, we seek to explore whether alternate social role configurations represent diverse pathways to equivalent levels of health and happiness, or whether some configurations appear intrinsically more challenging or risk-laden.

\section{Method}

\section{Sample}

Longitudinal data were obtained from the ongoing Monitoring the Future (MTF) project, which has recruited nationally representative samples of about 16,000 students in final year of secondary school ( $12^{\text {th }}$ grade; modal age 18 years) annually since 1975 (Johnston et al 2011a). Approximately 2,400 of these participants are selected each year for biennial follow-ups using mailed surveys. Illegal drug users are over-sampled for follow-up, thus sampling weights are used in analyses to best approximate population estimates. These longitudinal follow-ups begin one year after the baseline for a random half of the participants, and two years after the baseline for the other half; these two halves are combined in these analyses. Thus, longitudinal data collected at age 18 and at ages 25/26 (the fourth follow-up) are used in analyses reported here. Retention rates through the mid-20s typically exceed $60 \%$ for cohorts used here, and differential attrition analyses reveal that those retained are more likely to be female, to be white, to report higher high school grades/marks, to have more educated parents, and to report lower senior year drug use (e.g. Jager et al in press; Schulenberg et al 2005; Staff et al 2010)'.

The cohort described here as the 80 s cohort represented the high school graduating classes of 1976 and 1977 who were at modal ages 25 or 26 in 1983,1984 , or $1985(n=2,614)$, and the cohort described as the 90s cohort represented the high school graduating classes of 1988 and 1989 who were at modal ages 25 or 26 in 1995, 1996, or 1997 $(n=2,434)$. The $80 \mathrm{~s}$ cohort roughly parallels the National Child Development Study in Britain (Schoon et al 2012) and the Jyväskylä Longitudinal Study of Personality and Social Development in Finland (Räikkönen et al 2012), and the 90s cohort roughly parallels the British Cohort Study (Schoon et al 2012) and the Northern Finland Birth Cohort 1966 (SalmelaAro at al 2012).

\section{Measures}

Demographic and educational predictors (modal age 18)

Demographic indicators were assessed at age 18. These included gender, race, two-parent family, and parent education. Gender was coded such that male $=0$ and female=1. Race was coded with two dummy variables (for Black and Other race) with White as the reference group. Living with two biological parents (coded as 1) was distinguished from other family forms (0). Parental education was assessed with two questions, "What is the highest level of schooling your [mother/father] completed?" Responses were $1=$ Completed grade school or less, $2=$ Some high school, 3=Completed high school, 4=Some college, 5=Completed college, and $6=$ Graduate or professional school after college. If both parents responded to the question, the responses were summed and multiplied by 5 . If only one parent responded, his/her answer was multiplied by 10 , so that responses ranged from 10 to 60 .

Educational background was assessed as high school grade point average (GPA) and educational aspirations. High school GPA was measured with the question, "Which of the following best describes your average grade so far in high school?" based on a range of responses from 1=D (69\% or below) to 9=A (93\%-100\%). Grades of $A$ are the highest possible in the US system and $D$ is the lowest passing grade; one letter grade is obtained in each course each year and averaged.

Educational aspirations were based on the question, "How likely is it that you will do each of the following things after high school?" Responses included "Attend a technical or vocational school," "Serve in the armed forces," "Graduate from a two-year college program," "Graduate from college (four-year program)," and "Attend graduate or professional school after college" with a response choices for each of Definitely won't, Probably won't, Probably will, and Definitely will. College aspirations were coded to reflect clear intentions to pursue a 4-year college degree or attend graduate school. Individuals who responded that they definitely would graduate from a four-year college degree or attend graduate school were coded as 1 and all others were coded as 0 . Among those who did not have college aspirations(i.e. college aspirations $=0$ ), trade school aspirations were coded as 1 for those who reported that they would definitely do technical school, armed forces, or graduate from a two-year college program and all others were coded as 0 . 


\section{Social roles in early adulthood}

Participation in the big five social roles of adulthood was assessed via self-report at age 25 or 26 using categorical indicators. The percents in each role are reported in the first columns of Tables 1 (80s cohort) and 2 (90s cohort). Student status was distinguished in three categories: Full-time student, Part-time student, and Non-student. Educational attainment was coded at four categorical levels: Completed high school, Some college, Associate's (2year) degree, and Bachelor's (4-year) degree or higher. Four categories of employment were distinguished: Not employed, Homemaker, Parttime employee, and Full-time employee. Regarding residential independence, we distinguished cohort members who lived with parents from those who lived away from parents. Three categories of partnership were distinguished: Single, Cohabiting (but not married), and Married. Regarding parenthood, we distinguished cohort members who had no children, 1 child, and 2 or more children. 
Table 1. Weighted frequencies of social roles in mid-twenties for 80 s cohort: entire sample and four latent classes

\begin{tabular}{|c|c|c|c|c|c|c|c|c|c|c|}
\hline & \multicolumn{2}{|c|}{$\begin{array}{l}\text { Entire } \\
\text { Sample }\end{array}$} & \multicolumn{2}{|c|}{$\begin{array}{c}\text { Educated } \\
\text { Students w/o } \\
\text { Children } \\
(8 \%)\end{array}$} & \multicolumn{2}{|c|}{$\begin{array}{l}\text { Working Singles, } \\
\text { Living w/ Parents } \\
(16 \%)\end{array}$} & \multicolumn{2}{|c|}{$\begin{array}{c}\text { Educated } \\
\text { Workers w/o } \\
\text { Children } \\
(45 \%)\end{array}$} & \multicolumn{2}{|c|}{$\begin{array}{c}\text { Married Workers } \\
\text { w/ Children } \\
(31 \%)\end{array}$} \\
\hline & $\mathrm{N}$ & rel \% & $\mathrm{N}$ & rel \% & $\mathrm{N}$ & rel \% & $\mathrm{N}$ & rel \% & $\mathrm{N}$ & rel \% \\
\hline Number of cases & 2,614 & 100 & 199 & 100 & 429 & 100 & 1,183 & 100 & 804 & 100 \\
\hline \multicolumn{11}{|l|}{ Living arrangements } \\
\hline Lives with parents & 482 & 18.88 & 33 & 17.22 & 401 & 100.0 & 25 & 2.13 & 23 & 2.96 \\
\hline Lives away from home & 2,073 & 81.12 & 159 & 82.78 & 0 & 0.00 & 1,150 & 97.87 & 764 & 97.04 \\
\hline \multicolumn{11}{|l|}{ Relationship status } \\
\hline Married & 1,282 & 49.26 & 49 & 24.8 & 0 & 0.00 & 511 & 43.32 & 722 & 90.33 \\
\hline Cohabiting & 212 & 8.15 & 12 & 6.30 & 3 & 0.60 & 158 & 13.37 & 39 & 4.92 \\
\hline Single & 1,108 & 42.59 & 134 & 68.8 & 425 & 99.4 & 511 & 43.32 & 38 & 4.75 \\
\hline \multicolumn{11}{|l|}{ Parental status } \\
\hline No children & 1,723 & 66.21 & 181 & 92.81 & 347 & 81.06 & 1,165 & 98.73 & 31 & 3.83 \\
\hline 1 child & 503 & 19.32 & 11 & 5.82 & 58 & 13.56 & 15 & 1.27 & 418 & 52.29 \\
\hline 2 or more children & 377 & 14.48 & 3 & 1.37 & 23 & 5.38 & 0 & 0.00 & 351 & 43.88 \\
\hline \multicolumn{11}{|l|}{ Employment status } \\
\hline Other (laid off or unemployed) & 257 & 11.27 & 84 & 76.44 & 56 & 14.43 & 37 & 3.41 & 80 & 11.41 \\
\hline Full-time home maker & 173 & 7.57 & 0 & 0.00 & 5 & 1.30 & 0 & 0.00 & 168 & 23.86 \\
\hline Works part-time & 35 & 1.53 & 11 & 9.67 & 6 & 1.56 & 12 & 1.08 & 7 & 0.95 \\
\hline Works full-time & 1,819 & 79.63 & 15 & 13.90 & 319 & 82.71 & 1,035 & 95.51 & 449 & 63.78 \\
\hline \multicolumn{11}{|l|}{ Current college attendance } \\
\hline Full-time attendance & 212 & 8.25 & 184 & 92.45 & 13 & 3.05 & 0 & 0.00 & 16 & 2.02 \\
\hline Part-time attendance & 259 & 10.06 & 15 & 7.55 & 43 & 10.29 & 167 & 14.27 & 35 & 4.38 \\
\hline Not attending college & 2,102 & 81.68 & 0 & 0.00 & 359 & 86.66 & 1,001 & 85.73 & 741 & 93.60 \\
\hline \multicolumn{11}{|l|}{ Education } \\
\hline High-school or less & 975 & 37.39 & 1 & 0.34 & 163 & 38.12 & 333 & 28.18 & 479 & 59.71 \\
\hline Some college & 584 & 22.40 & 72 & 36.47 & 100 & 23.36 & 247 & 20.90 & 165 & 20.62 \\
\hline Associates/technical degree & 321 & 12.33 & 31 & 15.80 & 55 & 12.97 & 150 & 12.71 & 85 & 10.56 \\
\hline Bachelor's or advanced degree & 727 & 27.89 & 94 & 47.39 & 109 & 25.55 & 451 & 38.21 & 73 & 9.11 \\
\hline
\end{tabular}

Note. Participants were in senior year of high school in 1976 or 1977, and age 25/26 in 1983, 1984 or 1985 . Due to negligible amounts of missing data, most indicator counts do not add up to the total count. 
Table 2. Weighted frequencies of social roles in mid-twenties for 90s cohort: entire sample and four latent classes

\begin{tabular}{|c|c|c|c|c|c|c|c|c|c|c|}
\hline & \multicolumn{2}{|c|}{$\begin{array}{l}\text { Entire } \\
\text { Sample }\end{array}$} & \multicolumn{2}{|c|}{$\begin{array}{c}\text { Educated } \\
\text { Students w/o } \\
\text { Children] } \\
(9 \%) \\
\end{array}$} & \multicolumn{2}{|c|}{$\begin{array}{c}\text { Working Singles } \\
\text { Living w/ Parents } \\
(18 \%) \\
\end{array}$} & \multicolumn{2}{|c|}{$\begin{array}{c}\text { Educated Workers } \\
\text { w/o Children } \\
(46 \%) \\
\end{array}$} & \multicolumn{2}{|c|}{$\begin{array}{c}\text { Married Workers } \\
\text { w/ Children } \\
(27 \%) \\
\end{array}$} \\
\hline & $\mathrm{N}$ & rel\% & $\mathrm{N}$ & rel\% & $\mathrm{N}$ & rel \% & $\mathrm{N}$ & rel \% & $\mathrm{N}$ & rel \% \\
\hline Number of cases & 2,434 & 100 & 229 & 100 & 433 & 100 & 1,124 & 100 & 648 & 100 \\
\hline \multicolumn{11}{|l|}{ Living arrangements } \\
\hline Lives with parents & 495 & 20.76 & 30 & 13.30 & 425 & 100.0 & 3 & 0.30 & 37 & 6.02 \\
\hline Lives away from home & 1,891 & 79.24 & 198 & 86.70 & 0 & 0.00 & 1,116 & 99.70 & 577 & 93.98 \\
\hline \multicolumn{11}{|l|}{ Relationship status } \\
\hline Married & 970 & 39.99 & 42 & 18.27 & 23 & 5.32 & 398 & 35.54 & 508 & 78.55 \\
\hline Cohabiting & 299 & 12.32 & 31 & 13.45 & 3 & .62 & 195 & 17.38 & 71 & 10.99 \\
\hline Single & 1,157 & 47.69 & 156 & 68.27 & 406 & 94.06 & 527 & 47.08 & 68 & 10.47 \\
\hline \multicolumn{11}{|l|}{ Parental status } \\
\hline No children & 1,733 & 71.34 & 225 & 98.25 & 381 & 87.99 & 1,118 & 99.82 & 9 & 1.39 \\
\hline 1 child & 393 & 16.17 & 2 & 0.87 & 41 & 9.55 & 2 & 0.18 & 347 & 53.68 \\
\hline 2 or more children & 303 & 12.49 & 2 & 0.87 & 11 & 2.46 & 0 & 0.00 & 291 & 44.93 \\
\hline \multicolumn{11}{|l|}{ Employment status } \\
\hline Other (laid off or unemployed) & 222 & 10.54 & 103 & 83.92 & 33 & 8.94 & 29 & 2.69 & 57 & 10.50 \\
\hline Full-time home maker & 91 & 4.31 & 0 & 0.00 & 2 & 0.54 & 0 & 0.00 & 89 & 16.24 \\
\hline Works part-time & 47 & 2.22 & 20 & 16.08 & 12 & 3.16 & 13 & 1.25 & 2 & 0.37 \\
\hline Works full-time & 1,743 & 82.92 & 0 & 0.00 & 322 & 87.35 & 1,023 & 96.06 & 398 & 72.89 \\
\hline \multicolumn{11}{|l|}{ Current college attendance } \\
\hline Full-time attendance & 331 & 13.72 & 223 & 98.98 & 26 & 6.07 & 44 & 3.98 & 34 & 5.28 \\
\hline Part-time attendance & 265 & 11.00 & 2 & 1.02 & 72 & 16.87 & 155 & 13.88 & 36 & 5.59 \\
\hline Not attending college & 1,814 & 75.28 & 0 & 0.00 & 330 & 77.06 & 915 & 82.14 & 569 & 89.13 \\
\hline \multicolumn{11}{|l|}{ Education } \\
\hline High-school or less & 471 & 19.40 & 0 & 0.00 & 65 & 15.16 & 137 & 12.17 & 269 & 41.61 \\
\hline Some college & 578 & 23.82 & 37 & 16.18 & 112 & 25.99 & 218 & 19.44 & 211 & 32.68 \\
\hline Associates/technical degree & 284 & 11.70 & 25 & 10.88 & 65 & 15.16 & 120 & 10.65 & 74 & 11.51 \\
\hline Bachelor's or advanced degree & 1,094 & 45.08 & 165 & 72.94 & 188 & 43.70 & 649 & 57.74 & 92 & 14.20 \\
\hline
\end{tabular}

Note. Participants were in senior year of high school in 1988 or 1989, and age 25/26 in 1995, 1996 or 1997. Due to negligible amounts of missing data, most indicator counts do not add up to the total count. 


\section{Wellbeing at ages $\mathbf{2 5}$ to $\mathbf{2 6}$}

To assess wellbeing and adjustment in the mid20s, we focused on perceived global life satisfaction, economic independence, and lifestyle indicators of legal and illegal substance use.

Life satisfaction was based on the question, "How satisfied are you with life as a whole?" Responses ranged from 1=completely dissatisfied to $7=$ completely satisfied.

Economic independence. Participants were asked, "During all of last year (January 1 - December 31), how much of your financial support came from each of the following sources?" Responses were on a scale of $0=$ None $(0 \%)$ to $6=$ All $(100 \%)$ for a range of income sources (i.e. yourself, your spouse, your parents, unemployment compensation, welfare, and other). The proportion of income originating from the respondent and his or her spouse (if applicable) were summed to indicate economic independence, with responses ranging from $0 \%$ to $100 \%$.

Cigarette use (12 month) was measured with the question, "Which best describes your cigarette smoking in the last 12 months?" Response options were $1=$ Have not smoked at all, $2=$ Smoked once or twice, 3=Smoked occasionally but not regularly, 4=Smoked regularly but stopped or cut back, and $5=$ Smoke regularly now.

Alcohol use (lifetime and 12 month). Participants were asked, "On how many occasions (if any) have you had any alcoholic beverage to drink-more than just a few sips...[in your lifetime/during the last 12 months]?" Response options for each timeframe were $1=0$ occasions, 2=1-2 occasions, 3=3-5 occasions, 4=6-9 occasions, $5=10-19$ occasions, $6=20-39$ occasions, and $7=40$ or more.

Heavy drinking (2 week) was reported by the question, "During the last two weeks, how many times (if any) have you had five or more drinks in a row?" Response options were 1=None, 2=Once, $3=$ Twice, $4=3$ to 5 times, $5=6$ to 9 times, and $6=10$ or more times.

Marijuana use (lifetime and 12 month). Participants were asked, "On how many occasions (if any) have you used marijuana/hashish...[in your lifetime/during the last 12 months]?" Response options for each questions were $1=0$ occasions, $2=1-2$ occasions, $3=3-5$ occasions, 4=6-9 occasions, 5=10-19 occasions, 6=2039 occasions, and $7=40$ or more.
Use of illegal drugs other than marijuana (lifetime and 12 month). Using similar questions for lifetime and past 12 month use of a series of other illegal drugs, participants were coded as $1=$ used an illicit drug other than marijuana, or $0=$ did not use an illicit drug other than marijuana. Note that this measure does not include marijuana use. Both those coded as " 0 " and "1" may or may not have used marijuana.

\section{Plan of analysis}

Latent class analyses are designed to empirically identify homogeneous subsets of a larger population (Muthén 2004). When solutions are clear, their utility is strongest if identified subgroups represent meaningful types or classes that have strong face validity, clear inter-group discrimination, and useful predictive validity (Nylund et al 2007; Muthén 2004). Here, confidence in generalizability beyond the specific sample is enhanced (over and above our use of national samples) by replication of the observed classes across varied samples, as well as the observation of similar antecedents and correlates. All analyses were conducted within Mplus, Version 5.2 (Muthén and Muthén 1998-2009), and used a maximum likelihood estimator that is robust to nonnormality. All multigroup model comparisons involving non-categorical dependent variables were based on $\chi^{2}$ difference tests (Kline 1998), and those involving categorical dependent variables were based on log likelihood ratio tests (Johnson and Wichern 2002).

\section{Results}

\section{Latent class selection and description (Aim 1)}

In latent class analyses of both the 80s and 90s cohorts, a four-class solution was selected as the best fitting model. The optimal number of latent classes was based upon three criteria as outlined by Muthén (2004), Muthén and Muthén (2000), and Nylund et al (2007): (1) the Bayesian information criterion (BIC) statistic (the lower the value the better the fit of the model); (2) the classification quality, which can be determined by examining both the posterior probabilities and entropy values (higher values indicate a greater distinctiveness among the latent classes as well as a superior model); and (3) solution interpretability (i.e. is the solution practical and understandable?). Because MTF oversamples drug 
users for longitudinal follow-up, sampling weights were used in the latent class analyses to best approximate population estimates. Preliminary analyses indicated that the inclusion of sampling weights did not alter the latent class structure (i.e. number of classes extracted and the defining characteristics of each class were equivalent, whether or not sampling weights were applied).

Collectively, the different decision criteria clearly indicated that the optimal number of latent classes for both cohorts was four (see Table 3). For both cohorts, the BIC values decreased steadily through the 4-class solution, but then increased between the 4- and 5-class solutions. For the 90s cohort, entropy increased through the 4-class solution but then decreased between the 4- and 5-class solutions, and though the average posterior probability decreased across the 1- through 5-class solutions, it decreased most sharply between the 4-class and 5-class solutions. For the 80 s cohort, entropy increased through the 4-class solution but then decreased between the 4- and 5-class solutions, and the average posterior probability decreased most sharply between the 4- and 5-class solutions. Finally, as we cover in more detail below, for both the 80s and 90s cohorts, the 4-class solution resulted in a set of social role configurations that were both interpretable and practical.

\begin{tabular}{llccccc} 
Table 3. Statistics for decision criteria to determine optimal number of latent classes \\
number \\
\cline { 2 - 2 } & Fit Index & \multicolumn{5}{c}{ classes extracted } \\
\hline \multirow{3}{*}{ 90s cohort } & 1 & 2 & 3 & 4 & 5 \\
& BIC & 27,539 & 26,208 & 25,861 & $\mathbf{2 5 , 5 4 2}$ & 25,557 \\
& Entropy & NA & 0.758 & 0.830 & $\mathbf{0 . 8 6 6}$ & 0.808 \\
& Average posterior probability & NA & 0.931 & 0.919 & $\mathbf{0 . 9 1 7}$ & 0.861 \\
& BIC & 32,730 & 31,029 & 30,581 & $\mathbf{3 0 , 2 6 8}$ & 30,271 \\
& Entropy & NA & 0.671 & 0.823 & $\mathbf{0 . 8 5 7}$ & 0.767 \\
& Average posterior probability & NA & 0.893 & 0.931 & $\mathbf{0 . 9 2 5}$ & 0.860
\end{tabular}

Note: Optimal solutions are in bold.

Examination of the frequencies of the six indicators of adult social roles across the 4-class solutions revealed strong similarities in the patterns observed across the two cohorts. The order of presentation of the classes is based on two considerations: a rough conceptual ordering from fewer adult roles to more adult roles and the ordering that emerged in the latent class analyses.

As shown in Tables 1 and 2, the first two classes inhabited fewer adult role statuses, but differed in which adult roles they were engaged in. Members of the first class, Educated Students without Children ( $8 \%$ in 80 s cohort $/ 9 \%$ in 90 s cohort), were typically full-time students, had little involvement in full-time employment, and did not have children. Over fourfifths lived independently from parents, and about two-thirds were single. The level of education they had already achieved was the highest of all the classes. All participants in both cohorts who were classified as Working Singles Living with Parents
(16\%/18\%) reported living with their parents, almost all were single, and very few had children. Full-time employment was the norm, with small numbers in part-time education. Levels of education achieved were similar to sample levels in their respective cohorts.

The remaining two classes were engaged in more adult roles than the first two classes, but also differed from each other in important ways. Among both classes nearly all were living independently from parents and were not enrolled in education. In other respects, they evidenced different patterns. Those described as Educated Workers without Children (45\%/46\%) were working full-time, had no children, and had relatively high levels of achieved education. The proportions married, cohabiting, and single were similar to sample levels in both cohorts. In contrast the large majorities of those described as Married Workers with Children (31\%/27\%) were married or cohabiting and had at least one child. The majority 
were working full-time, with an additional onequarter/one-sixth being full-time homemakers. This group had the lowest levels of achieved education in both cohorts, with the modal response being a high school education.

\section{Late adolescent predictors of early adult latent class membership (Aim 2)}

The second objective was to examine age 18 demographic and educational predictors of class membership at age 25 to 26 . To test for latent class differences in age 18 demographic and educational predictors, for each cohort the indicator of latent class membership was saved using the "Save data" command within Mplus, and used as a grouping variable in subsequent multigroup analyses. Results are shown in Tables 4 and 5. Odds (i.e. [(percent yes)/(percent no)]) are listed for all categorical age 18 demographic and educational predictors. In these and all subsequent tables, superscripted letters indicate rank order mean differences in each indicator across a cohort's four latent classes (i.e. "a" indicates that a latent class was highest overall on that indicator, "b" indicates a latent class was second highest overall on that indicator, and so forth; latent classes with equivalent scores on an indicator share the same superscripted letter). Also in these and all subsequent tables, each significant complex or pair-wise group difference among the latent classes and the model comparison carried out to test for that difference share the same superscripted number. For example, in Table 4 the first notable group comparison " $4>1,2,3$ ", which compares the odds of being female for Married Workers with Children to the odds of being female of the other three latent classes, has a superscripted "1". The model comparison at the bottom of the table that shares the superscripted " 1 " $(2 \Delta L L(1)=40.05, p<.01)$ provides the results for this particular notable group comparison. 


\section{Table 4. Weighted latent class differences in adolescent predictors: 80 s cohort}

\section{Estimates by latent class}

\begin{tabular}{|c|c|c|c|c|c|}
\hline Entire sample & $\begin{array}{l}\text { (1) Educated } \\
\text { Students w/o } \\
\text { Children } \\
(8 \%)\end{array}$ & $\begin{array}{l}\text { (2) Working Singles } \\
\text { Living w/ Parents } \\
(16 \%)\end{array}$ & $\begin{array}{l}\text { (3) Educated } \\
\text { Workers w/o } \\
\text { Children } \\
(45 \%)\end{array}$ & $\begin{array}{l}\text { (4) Married Workers } \\
\text { w/ Children } \\
(31 \%)\end{array}$ & $\begin{array}{l}\text { Notable group } \\
\text { comparisons }\end{array}$ \\
\hline $1.17(1.08,1.26)^{*}$ & $0.80(0.61,1.04)^{b}$ & $0.97(0.81,1.16)^{b}$ & $1.07(0.96,1.19)^{b}$ & $1.63(1.43,1.87)^{* *^{a}}$ & $4>1,2,3^{1} ; 1=2=3^{2}$ \\
\hline $.11(0.09,0.12)^{* *}$ & $0.08(0.05,0.13)^{* *^{c}}$ & $0.18(0.14,0.23)^{* *^{a}}$ & $0.07(0.05,0.08)^{* * c}$ & $0.14(0.11,0.17)^{* *^{a}}$ & $2,4>1,3^{3} ; 2=4^{4} ; 1=3^{5}$ \\
\hline $.06(0.06,0.08)^{* *}$ & $0.09(0.06,0.15)^{* *^{a}}$ & $0.10(0.74,0.14)^{* *^{a}}$ & $0.05(0.04,0.06)^{* * c}$ & $0.06(0.05,0.08)^{* * c}$ & $1,2>3,4^{6} ; 1=2^{7} ; 3=4^{8}$ \\
\hline $.97(4.50,5.48)^{* *}$ & $5.33(3.70,7.67)^{* *^{a}}$ & $4.45(3.54,5.60)^{* *^{c}}$ & $6.44(5.50,7.53)^{* *^{a}}$ & $3.75(3.19,4.41)^{* *^{c}}$ & $1,3>2,4^{9} ; 1=3^{10} ; 2=4^{11}$ \\
\hline $33.11(11.65)$ & $40.28(13.13)^{a}$ & $31.51(11.21)^{c}$ & $34.80(11.30)^{b}$ & $29.50(10.57)^{d}$ & $1>3^{12} ; 3>2^{13} ; 2>4^{14}$ \\
\hline $5.92(1.87)$ & $6.71(1.74)^{\mathrm{a}}$ & $5.53(1.86)^{c}$ & $6.12(1.80)^{b}$ & $5.65(1.90)^{c}$ & $1>3^{15} ; 3>2,4^{16} ; 2=4^{17}$ \\
\hline $.39(0.36,0.43)^{* *}$ & $1.13(0.87,1.47)^{a}$ & $0.37(0.32,0.42)^{* *^{c}}$ & $0.48(0.43,0.54)^{* *^{\mathrm{b}}}$ & $0.20(0.17,0.24)^{* * d}$ & $1>3^{18} ; 3>2^{19} ; 2>4^{20}$ \\
\hline $.18(0.16,0.20)^{* *}$ & $0.10(0.07,0.16)^{* * d}$ & $0.16(0.12,0.21)^{* *^{b}}$ & $0.17(0.15,0.20)^{* *^{\mathrm{b}}}$ & $0.26(0.22,0.30)^{* *^{a}}$ & $4>2,3^{21} ; 2=3^{22} ; 2,3>1^{23}$ \\
\hline
\end{tabular}

Note. For continuous outcomes, standard deviations in parentheses. Model comparison results (listed below) and notable group comparisons (listed in last column, above) are matched by superscripted number.

${ }^{*} p<.05 ; * p<.01$. A significant odds estimate indicates an odds value that is different from 1.0 (i.e. a 50/50 odds).

${ }^{1} \Delta L L(1)=40.05, p<.01 \quad{ }^{5} 2 \Delta L L(1)=0.53, p=.47 \quad{ }^{9} 2 \Delta L L(1)=23.99, p<.01 \quad{ }^{13} \Delta \chi 2(1)=24.63, p<.01 \quad{ }^{17} \Delta \chi 2(1)=1.34, p=.25 \quad{ }^{21} \Delta L L(1)=8.49, p<.01$

${ }^{2} 2 \Delta L L(2)=4.96, p=.08 \quad{ }^{6} 2 \Delta L L(1)=13.16, p<.01 \quad{ }^{10} 2 \Delta L L(1)=1.00, p=.32 \quad{ }^{14} \Delta \chi 2(1)=9.40, p<.01 \quad{ }^{18} 2 \Delta L L(1)=39.35, p<.01 \quad{ }^{22} 2 \Delta L L(1)=0.17, p=.68$

${ }^{3} 2 \Delta L L(1)=42.92, p<.01{ }^{7} 2 \Delta L L(1)=0.22, p=.64 \quad{ }^{11} 2 \Delta L L(1)=1.67, p=.20 \quad{ }^{15} \Delta \chi 2(1)=16.49, p<.01 \quad{ }^{19} 2 \Delta L L(1)=6.30, p<.05 \quad{ }^{23} 2 \Delta L L(1)=5.40, p<.05$

${ }^{4} 2 \Delta L L(1)=2.63, p=.11 \quad{ }^{8} 2 \Delta L L(1)=1.95, p=.16 \quad{ }^{12} \Delta \chi^{2}(1)=29.20, p<.01 \quad{ }^{16} \Delta \chi 2(1)=52.12, p<.01 \quad{ }^{20} 2 \Delta L L(1)=23.39, p<.01$ 
Table 5. Weighted latent class differences in adolescent predictors: 90 s cohort

\section{Estimates by latent class}

$\begin{array}{cccccc}\text { Entire sample } & \begin{array}{c}\text { (1) Educated } \\ \text { Students w/o } \\ \text { Children }\end{array} & \begin{array}{c}\text { (2) Working Singles } \\ \text { Living w/ Parents }\end{array} & \begin{array}{c}\text { (3) Educated } \\ \text { Workers w/o } \\ \text { Children }\end{array} & \begin{array}{c}\text { (4) Married } \\ \text { Workers w/ } \\ \text { Children }\end{array} \\ \text { (9\%) } & (18 \%) & (46 \%) & (27 \%)\end{array}$

\begin{tabular}{|c|c|c|c|c|c|c|}
\hline Odds female & $1.31(1.21,1.42)^{*}$ & $1.10(0.86,1.42)^{b}$ & $1.10(0.92,1.32)^{b}$ & $1.20(1.07,1.34)^{*^{b}}$ & $1.87(1.60,2.19)^{* *^{a}}$ & $4>1,2,3^{1} ; 1=2=3^{2}$ \\
\hline Odds black & $0.08(0.07,0.10)^{* *}$ & $0.06(0.03,0.11)^{* * c}$ & $0.12(0.09,0.16)^{* *^{a}}$ & $0.05(0.04,0.07)^{* * c}$ & $0.11(0.09,0.14)^{* *^{a}}$ & $2,4>1,3^{3} ; 1=3^{4} ; 2=4^{5}$ \\
\hline Odds other race & $0.12(0.11,0.14)^{* *}$ & $0.12(0.08,0.18)^{* * b}$ & $0.18(0.14,0.23)^{* *^{a}}$ & $0.09(0.08,0.12)^{* * b}$ & $0.13(0.10,0.16)^{* * b}$ & $2>1,3,4^{6} ; 1=3=4^{7}$ \\
\hline Odds intact family & $3.64(3.31,4.00)^{* *}$ & $3.44(2.55,4.65)^{* *^{a}}$ & $4.90(3.85,6.25)^{* *^{a}}$ & $4.14(3.59,4.78)^{* *^{a}}$ & $2.57(2.17,3.03)^{* *^{d}}$ & $1=2=3^{8} ; 1,2,3>4^{9}$ \\
\hline Parents' average education & $38.39(11.81)$ & $45.24(11.71)^{a}$ & $36.70(12.02)^{c}$ & $40.25(11.38)^{b}$ & $33.78(10.37)^{d}$ & $1>3^{10} ; 3>2^{11} ; 2>4^{12}$ \\
\hline High-school GPA & $6.17(1.90)$ & $7.08(1.77)^{\mathrm{a}}$ & $5.83(1.89)^{\mathrm{c}}$ & $6.46(1.79)^{b}$ & $5.57(1.91)^{d}$ & $1>3^{13} ; 3>2^{14} ; 2>4^{15}$ \\
\hline $\begin{array}{l}\text { Odds pursue college } \\
\text { degree }\end{array}$ & $1.06(0.98,1.15)$ & $3.35(2.49,4.50)^{* *^{a}}$ & $0.89(0.74,1.07)^{c}$ & $1.55(1.38,1.73)^{*^{b}}$ & $0.42(0.35,0.49)^{* * d}$ & $1>3^{16} ; 3>2^{17} ; 2>4^{18}$ \\
\hline Odds pursue trade school & $0.19(0.17,0.21)^{* *}$ & $0.08(0.05,0.12)^{* * d}$ & $0.19(0.15,0.25)^{* * c}$ & $0.15(0.13,0.18)^{* *^{c}}$ & $0.32(0.27,0.38)^{* *^{a}}$ & $4>2,3^{19} ; 2=3^{20} ; 2,3>1^{21}$ \\
\hline
\end{tabular}

Note: For continuous outcomes, standard deviations in parentheses. Model comparison results (listed below) and notable group comparisons (listed in last column, above) are matched by superscripted number.

${ }^{*} p<.05{ }^{* *} p<.01$. A significant odds estimate indicates an odds value that is different from 1.0 (i.e. a 50/50 odds).

$\begin{array}{lllll}{ }^{1} 2 \Delta L L(1)=30.49, p<.01 & { }^{5} 2 \Delta L L(1)=0.08, p=.77 & { }^{9} 2 \Delta L L(1)=24.25, p<.01 & { }^{13} \Delta \chi^{2}(1)=19.92, p<.01 & { }^{17} 2 \Delta L L(1)=27.73, p<.01 \\ { }^{2} 2 \Delta L L(2)=0.86, p=.65 & { }^{6} 2 \Delta L L(1)=12.64, p<.01 & { }^{10} \Delta \chi^{2}(1)=29 L L(1)=11.13, p<.01 \\ { }^{3} 2 \Delta L L(1)=23.99, p<.01 & { }^{7} 2 \Delta L L(2)=3.82, p=.15 & { }^{11} \Delta \chi^{2}(1)=29.74, p<.01 & { }^{15} \Delta \chi^{2}(1)=4.99, p<.05 \quad{ }^{2}(1) 2 \Delta L L(1)=40.28, p<.01 \\ { }^{4} 2 \Delta L L(1)=1.32, p=.25 & { }^{8} 2 \Delta L L(2)=3.57, p=.17 & { }^{12} \Delta \chi^{2}(1)=17.10, p<.01 & { }^{16} 2 \Delta L L(1)=26.97, p<.01 & { }^{20} 2 \Delta L L(1)=3.14, p=.08\end{array}$ 
Observed results were similar across the two cohorts with some notable differences. In terms of age 18 demographics, females in both cohorts were more likely than males to be classified as being Married Workers with Children. In the 80s cohort, participants who were not from two-parent families were more likely to be classified as Married Workers with Children or Working Singles Living with Parents than classified as Educated Students without Children or Educated Workers without Children, and in the 90s cohort, they were more likely to be classified as Married Workers with Children than any other group. Turning to the educational background predictors, in both cohorts, the four latent classes were ordered similarly on their levels of parent education, student high school GPA, and aspirations to pursue a college degree. In their late adolescence, those classified as Educated Students without Children in early adulthood had the highest levels of these three predictors, followed by Educated Workers without Children, Working Singles Living with Parents, and then Married Workers with Children, in that order. Plans to pursue trade school were ordered differently, that is, Married Workers with Children had the highest odds of having said they aimed to pursue trade school, compared to the other three groups. These age 18 rankings for education were similar to the age 25/26 levels of education attained by the four classes, that is, individuals with higher parental education, high school GPA, and college aspirations at age 18 tended to be members of classes who achieved more education by ages 25/26. This pattern was observed in both cohorts, except that the differences between adjacently ranked groups were more distinct in the 90 s cohort. That is, more pairwise comparisons were significant than in the 80 s cohort.

\section{Latent class differences in young adult correlates (Aim 3)}

To test for latent class differences in young adult correlates, for each cohort we used the saved indicator of latent class membership as a grouping variable and conducted multiple-group analyses. Results are shown in Tables 6 and 7, which list odds (i.e. [(percent yes)/(percent no)]) for all categorical young adult correlates. In both cohorts, the two classes who were engaged in more adult social roles evidenced the highest economic independence as well as high life satisfaction. These groups reported annual cigarette use rates that were similar to the sample averages. In contrast, these two classes were the most dissimilar in terms of alcohol, marijuana, and other drug use. Specifically, the Educated Workers without Children class reported relatively high levels of use of these substances, and the Married Workers with Children class reported the lowest rates. 
Table 6. Weighted latent class differences in mid-twenties well-being correlates: 80 s cohort

\section{Estimates by latent class}

\author{
Entire sample
}

\section{(1) Educated \\ Students w/o \\ Children}

$(8 \%)$

12-month cigarette use

12-month alcohol use

Lifetime alcohol use

Heavy drinking

12-month marijuana use

Lifetime marijuana use

12-month OTM (odds)

Lifetime OTM (odds)

Economic independence

Life satisfaction

$2.26(1.67)$

$4.93(2.08)$

$6.28(1.58)$

$1.70(1.17)$

$2.43(2.20)$

$4.13(2.53)$

$0.43(0.40,0.46)^{* *}$

$1.09(1.01,1.17)^{*}$

$5.41(1.27)$

4.89 (1.50)

$2.00(1.58)^{d}$

$5.26(2.00)^{\mathrm{a}}$

$$
6.35(1.57)^{b}
$$

$1.66(1.07)^{c}$

$2.54(2.230)^{\mathrm{a}}$

$$
4.11(2.55)^{b}
$$

$0.43(0.32,0.58)^{* *^{b}}$

$1.14(1.03,1.32)^{*^{a}}$

$4.15(2.01)^{\mathrm{a}}$

$5.01(1.46)^{\mathrm{a}}$

\author{
(2) Working Singles \\ Living w/ Parents
}

(16\%)

$2.43(1.72)^{a}$

$4.93(2.07)^{c}$

$6.16(1.68)^{b}$

$1.83(1.27)^{\mathrm{a}}$

$2.42(2.17)^{\mathrm{a}}$

$4.00(2.51)^{b}$

$0.42(0.35,0.51)^{* * b}$

$0.94(0.79,1.13)^{c}$

$4.99(1.56)^{d}$

$4.47(1.52)^{d}$
(3) Educated

Workers w/o

Children

(45\%)

$\begin{array}{lc}\text { (4) Married } & \text { Notable group } \\ \text { Workers w/ } & \text { comparisons } \\ \text { Children } & \\ (31 \%) & \end{array}$

$2.22(1.63)^{b}$

$5.38(1.91)^{\mathrm{a}}$

$6.50(1.36)^{\mathrm{a}}$

$1.80(1.23)^{\mathrm{a}}$

$2.64(2.30)^{\mathrm{a}}$

$4.38(2.51)^{a}$

$0.55(0.50,0.62)^{* *^{a}}$

$1.27(1.13,1.42)^{* *^{\mathrm{a}}}$

$5.60(0.97)^{\mathrm{a}}$

$4.98(1.46)^{\mathrm{a}}$

$2.30(1.70)^{b}$

$4.16(2.13)^{d}$

$5.99(1.75)^{d}$

$1.47(.99)^{d}$

$2.09(2.02)^{d}$

$3.84(2.54)^{b}$

$0.28(0.24,0.32)^{* * d}$

$0.92(0.81,1.05)^{c}$

$5.66(1.00)^{a}$

$4.97(1.52)^{a}$

\begin{abstract}
$2>3,4^{1} ; 3=4^{2} ; 3,4>1^{3}$
$3=1^{4} ; 3,1>2^{5} ; 2>4^{6}$

$3>1,2^{7} ; 1=2^{8} ; 1,2>4^{9}$

$2=3^{10} ; 2,3>1^{11} ; 1>4^{12}$

$1=2=3^{13} ; 1,2,3>4^{14}$

$3>1,2,4^{15} ; 1=2=4^{16}$

$3>1,2^{17} ; 1=2^{18} ; 1,2>4^{19}$

$1=3^{20} ; 2=4^{21} ; 1,3>2,4^{22}$

$3=4^{23} ; 3,4>2^{24} ; 2>1^{25}$

$1=3=4^{26} ; 1,3,4>2^{27}$
\end{abstract}

Note: For continuous outcomes, standard deviations in parentheses. Model comparison results (listed below) and notable group comparisons (listed in last column, above) are matched by superscripted number. OTM-Drugs Other than Marijuana.

${ }^{*} p<.05 ; * p<.01$. A significant odds estimate indicates an odds value that is different from 1.0 (i.e. a 50/50 odds).
${ }^{1} \Delta \chi^{2}(1)=4.87, p<.05$
${ }^{6} \Delta \chi^{2}(1)=35.88, p<.001{ }^{11} \Delta \chi^{2}(1)=4.06, p<.05$
${ }^{16} \Delta \chi^{2}(2)=2.68, p=.26$
${ }^{21} 2 \Delta L L(1)=0.04, p=.85 \quad{ }^{26} \Delta \chi^{2}(2)=0.17, p=.92$
${ }^{2} \Delta \chi^{2}(1)=1.52, p=.22$
${ }^{7} \Delta \chi^{2}(1)=90.41, p<.001{ }^{12} \Delta \chi^{2}(1)=7.70, p<.01$
${ }^{17} 2 \Delta L L(1)=7.84, p<.01$
${ }^{22} 2 \Delta L L(1)=17.74, p<.001{ }^{27} \Delta \chi^{2}(1)=44.64, p<.001$
${ }^{3} \Delta \chi^{2}(1)=3.89, p<.05$
${ }^{8} \Delta \chi^{2}(1)=1.54, p=.21$
${ }^{13} \Delta \chi^{2}(2)=3.64, p=.16$
${ }^{18} 2 \Delta L L(1)=0.01, p=.91 \quad{ }^{23} \Delta \chi^{2}(1)=1.52, p=.22$
${ }^{4} \Delta \chi^{2}(1)=0.74, p=.39$
${ }^{9} \Delta \chi^{2}(1)=4.39, p<.05$
${ }^{14} \Delta \chi^{2}(1)=41.77, p<.001$
${ }^{19} 2 \Delta L L(1)=15.70, p<.001{ }^{24} \Delta \chi^{2}(1)=92.59, p<.001$
${ }^{5} \Delta \chi^{2}(1)=16.99, p<.001{ }^{10} \Delta \chi^{2}(1)=0.16, p=.69$
${ }^{15} \Delta \chi^{2}(1)=23.39, p<.001$
${ }^{20} 2 \Delta L L(1)=0.60, p=.44 \quad{ }^{25} \Delta \chi^{2}(1)=42.12, p<.001$ 
Table 7. Weighted latent class differences in mid-twenties well-being correlates: 90s cohort

\section{Estimates by latent class}

\begin{tabular}{|c|c|c|c|c|c|c|}
\hline & Entire sample & $\begin{array}{l}\text { (1) Educated } \\
\text { Students w/o } \\
\text { Children } \\
(9 \%)\end{array}$ & $\begin{array}{l}\text { (2) Working Singles } \\
\text { Living w/ Parents } \\
(18 \%)\end{array}$ & $\begin{array}{l}\text { (3) Educated } \\
\text { Workers w/o } \\
\text { Children } \\
(46 \%)\end{array}$ & $\begin{array}{l}\text { (4) Married } \\
\text { Workers w/ } \\
\text { Children } \\
(27 \%)\end{array}$ & $\begin{array}{l}\text { Notable group } \\
\text { comparisons }\end{array}$ \\
\hline 12-month cigarette use & $1.92(1.43)$ & $1.69(1.23)^{d}$ & $1.88(1.43)^{\mathrm{a}}$ & $1.93(1.42)^{\mathrm{a}}$ & $2.01(1.52)^{a}$ & $2=3=4^{1} ; 2,3,4>1^{2}$ \\
\hline 12-month alcohol use & $4.42(2.08)$ & $4.70(1.99)^{b}$ & $4.23(2.08)^{c}$ & $5.04(1.89)^{\mathrm{a}}$ & $3.37(1.99)^{d}$ & $3>1^{3} ; 1>2^{4} ; 2>4^{5}$ \\
\hline Lifetime alcohol use & $6.07(1.70)$ & $6.19(1.68)^{b}$ & $5.83(1.84)^{c}$ & $6.43(1.33)^{\mathrm{a}}$ & $5.56(1.99)^{d}$ & $3>1^{6} ; 1>2^{7} ; 2>4^{8}$ \\
\hline Heavy drinking & $1.60(1.09)$ & $1.54(0.97)^{c}$ & $1.66(1.20)^{\mathrm{a}}$ & $1.73(1.17)^{\mathrm{a}}$ & $1.34(0.82)^{d}$ & $2=3^{9} ; 2,3>1^{10} ; 1>4^{11}$ \\
\hline 12-month marijuana use & $1.64(1.55)$ & $1.69(1.58)^{\mathrm{a}}$ & $1.53(1.42)^{c}$ & $1.78(1.68)^{\mathrm{a}}$ & $1.46(1.33)^{c}$ & $\begin{array}{c}1=3^{12} ; 2=4^{13} \\
1,3>2,4^{14}\end{array}$ \\
\hline Lifetime marijuana use & $2.94(2.29)$ & $3.00(2.33)^{\mathrm{a} \mid \mathrm{b}}$ & $2.49(2.14)^{d}$ & $3.20(2.35)^{a}$ & $2.79(2.20)^{\mathrm{b}}$ & $\begin{array}{c}3>4^{15} ; 4>2^{16} ; 1>2^{17} ; \\
1=3^{18} ; 1=4^{19}\end{array}$ \\
\hline 12-month OTM (odds) & $0.10(0.92,0.12)^{* *}$ & $0.11(0.08,0.17)^{* *^{a}}$ & $0.09(0.06,0.12)^{* *^{a}}$ & $0.12(0.10,0.14)^{* *^{a}}$ & $0.10(0.07,0.12)^{* *^{a}}$ & $1=2=3=4^{20}$ \\
\hline Lifetime OTM (odds) & $0.44(0.41,0.48)^{* *}$ & $0.43(0.33,0.56)^{* *^{a}}$ & $0.31(0.25,0.38)^{* * d}$ & $0.51(0.45,0.57)^{* *^{a}}$ & $0.45(0.38,0.52)^{* *^{a}}$ & $1=3=4^{21} ; 1,3,4>2^{22}$ \\
\hline Economic independence & $5.33(1.32)$ & $3.74(2.01)^{d}$ & $5.05(1.44)^{c}$ & $5.55(0.98)^{b}$ & $5.67(0.95)^{\mathrm{a}}$ & $4>3^{23} ; 3>2^{24} ; 2>1^{25}$ \\
\hline Life satisfaction & $5.09(1.40)$ & $5.08(1.42)^{a}$ & $4.87(1.44)^{d}$ & $5.15(1.35)^{a}$ & $5.13(1.45)^{\mathrm{a}}$ & $1=3=4^{26} ; 1,3,4>2^{27}$ \\
\hline
\end{tabular}

Note: OTM- Drugs Other than Marijuana. For continuous outcomes, standard deviations in parentheses. Model comparison results (listed below) and notable group comparisons (listed in last column, above) are matched by superscripted number.

${ }^{*} p<.05{ }^{* *} p<.01$. A significant odds estimate indicates an odds value that is different from 1.0 (i.e. a 50/50 odds).
${ }^{1} \Delta \chi^{2}(1)=2.22, p=.33 \quad{ }^{6} \Delta \chi 2(1)=7.29, p<.01 \quad{ }^{11} \Delta \chi^{2}(1)=12.95, p<.001$
${ }^{16} \Delta \chi^{2}(2)=5.61, p<.05 \quad{ }^{21} 2 \Delta \mathrm{LL}(2)=2.41, p=.30$
${ }^{26} \Delta \chi^{2}(2)=0.64, p=.73$
${ }^{2} \Delta \chi^{2}(1)=6.55, p<.05 \quad{ }^{7} \Delta \chi^{2}(1)=4.97, p<.05 \quad{ }^{12} \Delta \chi^{2}(1)=0.58, p=.45$
${ }^{17} \Delta \chi^{2}(1)=9.57, p<.01$
${ }^{22} 2 \Delta \operatorname{LL}(1)=15.31, p<.001{ }^{27} \Delta \chi^{2}(1)=14.38, p<.001$
${ }^{3} \Delta \chi ?^{2}(1)=6.78, p<.01 \quad{ }^{8} \Delta \chi^{2}(1)=4.89, p<.05 \quad{ }^{13} \Delta \chi^{2}(1)=0.88, p=.35$
${ }^{18} \Delta \chi^{2}(1)=1.40, p=.24 \quad{ }^{23} \Delta \chi^{2}(1)=5.22, p<.05$
${ }^{4} \Delta \chi^{2}(1)=7.93, p<.01 \quad{ }^{9} \Delta \chi^{2}(1)=1.24, p=.27 \quad{ }^{14} \Delta \chi^{2}(1)=23.84, p<.001$
${ }^{19} \Delta \chi^{2}(1)=1.58, p=.21 \quad{ }^{24} \Delta \chi^{2}(1)=103.62, p<.001$
${ }^{5} \Delta \chi^{2}(1)=45.81, p<.001{ }^{10} \Delta \chi^{2}(1)=4.88, p<.05{ }^{15} \Delta \chi^{2}(1)=13.60, p<.001$
${ }^{20} 2 \Delta \mathrm{LL}(1)=3.37, p=.34{ }^{25} \Delta \chi^{2}(1)=121.93, p<.001$ 
The Educated Students without Children and Working Singles Living with Parents classes also evidenced similar patterns across cohorts in terms of their economic independence and life satisfaction. Educated Students without Children in both cohorts had the lowest levels of economic independence, yet their life satisfaction was as high as both faster track groups. Working Singles Living with Parents had medium economic independence but the lowest life satisfaction in both cohorts. Patterns of substance use were less consistent across cohorts for Educated Students without Children and Working Singles Living with Parents, except that the Working Singles had higher annual smoking prevalence and Educated Students had the lowest. Levels of alcohol, marijuana, and other drug use for these two classes tended to fall in between the relatively high drug use of the Educated Workers without Children class and the relatively low drug use of the Married Workers with Children.

\section{Discussion}

The transition to adulthood in recent decades has lengthened and diversified (Arnett 2000; Bynner 2005; Settersten 2007), not least in the United States which has great wealth but also high social inequality in income, health, and education coupled with relatively limited social safety nets in comparison with Europe (United Nations 2010; World Factbook 2011). For example, in the US in 1984, the median age of first marriage was 25.4 for men and 23.0 for women and the mean age of mother at the birth of her first child was 23.5. In 1996 by contrast, the median age of first marriage was 27.1 for men and 24.8 for women and the mean age of mother at the birth of her first child was 24.6 (Mathews and Hamilton 2002; US Census Bureau 2006). Across many nations, the passage to adulthood has become also become marked by more heterogeneity in the timing and content of social role changes. However, despite these changes and challenges, we identified four clear cross-sectional configurations of social roles that were remarkably similar in two cohorts separated by 12 years, as well as similar to those observed in two cohorts roughly matched in historical time in Britain (Schoon et al 2012) and Finland (Räikkönen et al 2012; Salmela-Aro et al 2012). The patterns are also relatively consistent with prior studies using latent class analyses (e.g. Osgood et al 2005; Sandefur et al 2005).

Why would social roles tend to cluster together in cohesive patterns? First, at a particular point in time, the successful pursuit of specific combinations of social roles may be mutually facilitative or inhibitive. For example, the income earned through longer-term full-time employment makes residential independence more possible. The support of a stable romantic partnership may promote a desire or practical support to become a parent. Conversely, the demands of parenthood or full-time education may make employment more challenging, though a source of income would facilitate the pursuit of both these roles. Second, over time, as Bynner et al (2005) argued, prior achievements and already-adopted roles may impose constraints or at least mount challenges to the unbridled pursuit of new role adoptions and achievements. For example, in the mid-20s, it may be practically easier for a person with a college degree to return to full-time education than a person with a high school diploma, due to financial, academic, and other resources. In this way, betweenperson (or between-class) heterogeneity may increase over time.

Educated Workers without Children and Married Workers with Children can both be characterized as having taken faster tracks to adult roles, in that they were not involved in education, they lived independently from parents, and they evidenced high levels of full-time employment or homemaker status. At the same time, the Educated Workers without Children class came from more advantaged family backgrounds (e.g. higher parental education) and had achieved more higher education. Those in the Married Workers with Children class, as implied by their class label, were almost all married and had children by their mid-20s, whereas there was great diversity in the partnership status of the Educated Workers without Children group, almost none of whom were parents. Alcohol and marijuana use in the two groups were very different, as previously shown in research examining links between marriage and parenthood and reduced substance use during the 20s through midlife (e.g. Bachman et al 1997; Staff et al 2012). Yet despite the many differences in the daily realities of their lives, the groups reported similar levels of life satisfaction and economic independence. 
As Settersten (2007) noted, "Young adulthood is a time when people begin to sort out commitments to persons, jobs, values, and ideologies. The realization that these commitments not only matter, but that they can actually be associated with happiness and life satisfaction even when they limit autonomy, is a symbol of maturity" (p. 257). It would appear that these young adults may have found some fulfillment in these adult roles.

The Educated Students without Children and the Working Singles Living with Parents could be seen as having taken slower tracks to adulthood. Again similarities and differences can be noted. Both groups tended to be single and few had children. However, Educated Students were typically in full-time education and tended to be more highly educated (even while still studying), while Working Singles were very seldom enrolled in any schooling and had more average levels of achieved education. Educated Students were likely to live away from parents while Working Singles lived in the parental home. Educated Students had the lowest levels of economic independence while Working Singles had medium economic independence. Life satisfaction of Educated Students was as high as both faster track groups, whereas Working Singles had the lowest levels of life satisfaction. Turning to substance use, Working Singles had higher annual smoking prevalence and Educated Students had the lowest; levels of other substance use for these two groups tended to fall in between the relatively high alcohol, marijuana, and other drug use of the Educated Workers without Children class and the relatively low use of these substances of the Married Workers with Children class. Overall, those classified as Educated Students were the most economically dependent, but it did not appear to negatively impact their life satisfaction, perhaps because their economic dependence is understood to be temporary and/or due to their own volition (i.e. continuing in higher education was likely their choice and viewed as in pursuit of a valued goal). Working Singles, who were the most likely to still live with their parents and who reported the lowest levels of life satisfaction, may have had the sense that they were stuck somewhere between adolescence and adulthood.

Finally, we also compare the Educated Students without Children with the Educated Workers without
Children classes. These groups came from more advantaged backgrounds, achieved higher levels of education, were very unlikely to be parents by their mid-20s, and had similar (though not identical) partnering profiles. Given the consistent documentation of higher rates of substance use among college students in the 18-22 year old age range (e.g. O'Malley and Johnston 2002), it may appear surprising that those who were working had higher rates of some substance use than the Student group. We suggest two possible explanations. First, we speculate a selection effect that draws attention to the age (mid-20s) and relatively high achieved education level of the Students. Given the relatively small size of the Student group (less than 10 percent in both cohorts), we speculate that many of these may be more academically-inclined and currently means-limited graduate students, whereas those childless, single/cohabiting workers within the Educated Workers without Children group likely have greater time and resources to continue their youthful social life beyond their college years (see also Amato and Kane 2011). Second, some prior comparisons of the substance use of students and non-students have not distinguished among the other social roles of the non-students, as we do here.

What configuration of social roles could best be described as thriving? There is no immediately apparent answer to this question. On the basis of our subjective and most general indicator, self-reported life satisfaction, in both cohorts three groups report similarly high life satisfaction, distinguished only from the Working Singles Living with Parents who were least satisfied with their lives. These three more satisfied groups were very different in their combinations of social roles, suggesting that there is clearly more than one pattern of role configuration that may support satisfaction. These three groups were all actively engaged in some meaningful social roles or goal pursuits, with Educated Students pursuing higher education and the Educated Workers and Married Workers groups engaged in employment and/or parenting. Consistent with age norms for the mid-20s (Settersten 1998), these three more satisfied groups had higher rates of independent living, unlike the working singles who all lived with their parents. It is tempting to attribute the lower life satisfaction of this latter group to their lack of residential 
independence, but the specific mechanisms underlying such an association require further elaboration. It is unknown whether it is the circumstances that led to not leaving or to returning to the parental home that are challenging (e.g. underemployment, divorce, parental illness) or the realities of sharing the home (e.g. inter-generational conflict, lack of privacy) (Valentine 2003).

\section{Limitations and strengths}

Of course, our study does have some limitations. First, because the sample included only those who completed high school, generalizability to those who dropped out of high school is limited. High school dropout rates among 16-24 year olds in 1976-1977 and 1988-1989 ranged from $12.6 \%$ to $14.1 \%$ nationally, and differed by race/ethnicity ranging from roughly one-tenth among Whites, one-sixth to one-fifth among Blacks, and one-third among Hispanics (note, however, that the high school completion rate has been improving in recent years; US Department of Commerce 2010). Individuals who leave school prior to high school graduation may combine roles in different ways and experience additional challenges. Second, role configurations at only one point in time were examined. Future research may fruitfully explore patterns of change in role configurations across the transition to adulthood. Third, role configurations may also differ in complex ways by gender and by additional demographic variables such as family social class background or race/ethnicity. For example some recent work has shown that gender differences in the timing of marriage and residential parenthood may underlie differences in the likelihood of inhabiting specific configurations (e.g. Oesterle et al 2010; Sandefur et al 2005).

An important strength of this study is the use of panel data collected from two nationally representative cohorts of US $12^{\text {th }}$ grade high school students followed for an eight year period into the mid-20s, allowing us more confidence about the generalizability of the findings, as well as the sufficient coverage of time during which high school plans about the future unfold. The inclusion of two different senior year cohorts, both with the exact same sets of procedures and measures, allows us greater confidence about the replicability over history. Results were very similar for those who passed through their 20s 12 years apart, in the 1980s and the 1990s. For example, although there were historical differences in the timing of marriage between the cohorts, the combination of marriage with other social role changes was similar. As noted at the outset of this paper, scholars agree that the transition to adulthood has lengthened and diversified since the 1950s. In our comparison of these two cohorts who came of age in the 1980s and 1990s, however, we see clear similarities in the patterns and prevalence of how young people in their mid-20s combine social roles.

\section{Acknowledgements}

This study was funded by support from the US National Institute on Drug Abuse (R01DA01411 and R01DA016575 to L. Johnston). Collaboration was facilitated by a grant from the US National Science Foundation (No. 0818478). The content here is solely the responsibility of the authors and does not necessarily represent the official views of the sponsors. 


\section{References}

Amato PR, Booth A, Johnson D and Rogers S. (2007) Alone together: how marriage in America is changing. Harvard University Press, Cambridge, MA.

Amato, PR and Kane, J B. (2011). Life-course pathways and the psychosocial adjustment of young adult women. Journal of Marriage and the Family, 73, 279-295.

Arnett JJ. (2000) Emerging adulthood: a theory of development from the late teens through the twenties. American Psychologist, 55, 469-480.

Bachman JG, Wadsworth KN, O'Malley PM, Johnston LD and Schulenberg JE. eds. (1997) Smoking, drinking, and drug use in young adulthood: the impacts of new freedoms and new responsibilities. Lawrence Erlbaum, Mahwah, NJ.

Bachman JG, Wadsworth KN, O'Malley P, Schulenberg J and Johnston LD. (1997) Marriage, divorce and parenthood during the transition to young adulthood: drug use and abuse. In J Schulenberg, JL Maggs and K Hurrelmann. eds. Health risks and developmental transitions during adulthood. Pp 246-279. Cambridge University Press, New York.

Beck U. (1992) Risk society. Sage, London.

Bell L, Burtless G, Gornick J and Smeeding TM. (2007) Failure to launch: Cross-national trends in the transition to economic independence. In S Danziger and CE Rouse. eds. The price of independence: the economics of early adulthood. Pp. 27-55. Russell Sage Foundation, New York.

Bynner J. (2005) Rethinking the youth phase of the life-course: The case for emerging adulthood? Journal of Youth Studies, 8, 367-384.

Cook TD and Furstenberg FF. (2002) Explaining aspects of the transition to adulthood in Italy, Sweden, Germany, and the United States: A cross-disciplinary, case synthesis approach. Annals of the American Academy of Political and Social Science, 580, 257-287.

Cooksey EC and RIndfuss RR. (2001) Patterns of work and schooling in young adulthood. Sociological Forum, 16, 731-755.

Côté J and Bynner JM. (2008) Changes in the transition to adulthood in the UK and Canada: The role of structure and agency in emerging adulthood. Journal of Youth Studies, 11, 251-268.

Dannefer D. (2003) Cumulative advantage/disadvantage and the life course: Cross-fertilizing age and social science theory. Journals of Gerontology: Social Sciences, 58B, S327-S337.

Danziger S and Rouse CE. (2007) The price of independence: the economics of early adulthood. Russell Sage Foundation, New York.

DeNavas-Walt C, Proctor BD and Smith JD. (2010) Income, poverty, and health insurance coverage in the United States: 2009. U.S. Census Bureau, Current Population Reports. Pp 60-238. US Government Printing Office, Washington, DC.

Fussell E and Furstenberg FF. (2005) The transition to adulthood during the twentieth century: Race, nativity, and gender. In RA Settersten Jr,, FF Furstenberg and RG Rumbaut. (2005) On the frontier to adulthood: theory, research, and public policy. Pp. 29-75. University of Chicago Press, Chicago.

Galambos NL, Barker ET and Krahn HJ. (2006) Depression, self-esteem, and anger in emerging adulthood: Sevenyear trajectories. Developmental Psychology, 42, 350-365.

Goldin C and Katz LF. (2007) Long range changes in the U.S. wave structure: narrowing, widening, polarizing. National Bureau of Economic Research Working Paper Series 13568.

Jager J, Schulenberg JE, O'Malley PM and Bachman JG. (in press) Historical variation in rates of change in substance use across the transition to adulthood: The trend towards lower intercepts and steeper slopes. Development and Psychopathology.

Johnson, RA. and Wichern, DW. (2002). Applied multivariate statistical analyses ( $5^{\text {th }}$ ed.). Upper Saddle River, NJ: Prentice Hall.

Johnston LD, O'Malley PM, Bachman JG and Schulenberg JE. (2011a) Monitoring the Future national survey results on drug use, 1975-2010. Volume I: Secondary school students. University of Michigan, Ann Arbor, MI.

Johnston LD, O'Malley PM, Bachman JG and Schulenberg JE. (2011b) Monitoring the Future national survey results on drug use, 1975-2010. Volume II: College students and adults ages 19-50. University of Michigan, Ann Arbor, MI.

Kline, RG. (1998). Principles and practice of structural equation modeling. New York, NY: Guilford Press. 
Levy H. (2007) Health insurance and the transition to adulthood. In S Danziger and CE Rouse. eds. The price of independence: the economics of early adulthood. Pp. 84-106. Russell Sage Foundation, New York.

Mathews TJ and Hamilton BE. (2002) Mean age of mother, 1970-2000. National vital statistics reports, 51(1). Hyattsville, Maryland: National Center for Health Statistics. Retrieved from http://www.cdc.gov/nchs/data/nvsr/nvsr51/nvsr51 01.pdf, April 24, 2012.

Muthén B. (2004) Latent variable analysis: Growth mixture modeling and related techniques for longitudinal data. In D Kaplan. ed. Handbook of Quantitative Methodology for the Social Sciences. Pp 345-368. Sage Publications, Los Angeles, CA.

Muthén B and Muthén L. (2000) Integrating person-centered and variable-centered analyses: Growth mixture modeling with latent trajectory classes. Alcoholism: Clinical and Experimental Research, 24, 882-891.

Muthén L and Muthén B. (1998-2009). Mplus user's guide ( $5^{\text {th }}$ ed.). Los Angeles, CA: Muthén \& Muthén.

Nylund KL, Asparouhov T and Muthén B. (2007) Deciding on the number of classes in latent class analysis and growth mixture modeling. A Monte Carlo simulation study. Structural Equation Modeling, 14, 535-569.

Oesterle S, Hawkins DJ, Hill KG and Bailey JA. (2010) Men's and women's pathways to adulthood and their adolescent precursors. Journal of Marriage and the Family, 72, 1436-1453.

O'Malley PM and Johnston LD. (2002) Epidemiology of alcohol and other drug use among American college students. Journal of Studies on Alcohol, Supplement No. 14, 23-39.

Osgood DW, Foster EM, Flanagan C and Ruth G. eds. (2006) On your own without a net: the transition to adulthood for vulnerable populations. University of Chicago Press, Chicago.

Osgood DW, Ruth G, Eccles JS, Jacobs JE and Barber BL. (2005) Six paths to adulthood: Fast starters, parents without careers, educated partners, educated singles, working singles, and slow starters. In RA Settersten Jr, FF Furstenberg and RG Rumbaut. eds. On the frontier to adulthood: theory, research, and public policy. Pp. 320-355. University of Chicago Press, Chicago.

Räikkönen E, Kokko K and Pulkkinen L. (2012) Patterns of adult roles, their antecedents and psychosocial wellbeing correlates among Finns born in 1959. Longitudinal and Life Course Studies, 3, 211-227.

Salmela-Aro K, Ek E, Taanila A and Chen M. (2012) Role configurations in young adulthood, antecedents, and later wellbeing among Finns born in 1966. Longitudinal and Life Course Studies, 3, 228-242.

Sandefur GD, Eggerling-Boeck J and Park H. (2005) Off to a good start? Postsecondary education and early adult life. In RA Settersten Jr. FF Furstenberg and RG Rumbaut. eds. On the frontier to adulthood: theory, research, and public policy. Pp. 292-319. University of Chicago Press, Chicago.

Schoeni RF and Ross KE. (2005) Material assistance from families during the transition to adulthood. In RA Settersten Jr, FF Furstenberg and RG Rumbaut. eds. On the frontier to adulthood: theory, research, and public policy. Pp. 396-416. University of Chicago Press, Chicago.

Schoon I, Kneale D, Jager J and Chen M. (2012) Becoming adults in Britain: lifestyles and wellbeing in times of social change. Longitudinal and Life Course Studies, 3, 173-189.

Schulenberg JE, Bryant AL and O'Malley PM. (2004) Taking hold of some kind of life: How developmental tasks relate to trajectories of wellbeing during the transition to adulthood. Development and Psychopathology, 16, 1119-1140.

Schulenberg JE, Maggs JM and O'Malley PM. (2003) How and why the understanding of developmental continuity and discontinuity is important: the sample case of long-term consequences of adolescent substance use. In JT Mortimer and MJ Shanahan. eds. Handbook of the life course. Pp. 413-436. Plenum Publishers, New York.

Schulenberg JE, Merline AC, Johnston LD, O'Malley PM, Bachman JG and Laetz VB. (2005) Trajectories of marijuana use during the transition to adulthood: the big picture based on national panel data. Journal of Drug Issues, 35, 255-279.

Schulenberg JE and Zarrett NR. (2006) Mental health during emerging adulthood: Continuity and discontinuity in courses, causes, and functions. In JJ Arnett and JL Tanner. eds. Emerging adults in America: coming of age in the 21st century. Pp. 135-172. American Psychological Association, Washington DC.

Settersten Jr RA. (1998) A time to leave home and a time never to return? Age constraints on the living arrangements of young adults. Social Forces, 76, 1373-1400.

Settersten Jr RA. (2005) Social policy and the transition to adulthood: Toward stronger institutions and individual capacities. In RA Settersten Jr, FF Furstenberg and RG Rumbaut. eds. On the frontier to adulthood: theory, research, and public policy. Pp. 534-560. University of Chicago Press, Chicago. 
Settersten Jr RA. (2007a) Passages to adulthood: Linking demographic change and human development. European Journal of Population, 23, 251-272.

Settersten Jr RA. (2007b) Social relationships in the new demographic regime: Potentials and risks, reconsidered. Advances in Life Course Research, 12, 3-28.

Settersten Jr RA. (2009) It takes two to tango: The (un)easy dance between life-course sociology and life-span psychology. Advances in Life Course Research, 14, 74-81.

Settersten Jr RA. (2007) The new landscape of adult life: Road maps, signposts, and speed lines. Research in Human Development, 4, 239-252.

Settersten Jr RA. Furstenberg FF and Rumbaut RG. (2005) On the frontier to adulthood: theory, research, and public policy. University of Chicago Press, Chicago.

Shanahan MJ. (2000) Pathways to adulthood in changing societies: Variability and mechanisms in life course perspective. Annual Review of Sociology, 26, 667-692.

Staff J, Greene K, Maggs JL and Schoon I. (2012) Family and work transitions and changes in drinking across adulthood. Manuscript in review.

Staff J, Schulenberg JE, Maslowsky J, Bachman JG, O‘Malley PM, Maggs JL and Johnston LD. (2010) Substance use changes and social role transitions: Proximal developmental effects on ongoing trajectories from late adolescence through early adulthood. Development and Psychopathology, 22 (Special issue: Developmental cascades: Part 2), 917-932.

United Nations Development Programme. (2010) Human development report 2010. The real wealth of nations: pathways to human development. United Nations Development Programme, New York. Accessed March 24, 2011, http://hdr.undp.org/en/reports/global/hdr2010/.

U.S. Census Bureau. (2006) Table MS-2. Estimated median age at first marriage, by sex: 1890 to the present. Retrieved from http://www.census.gov/population/socdemo/hh-fam/ms2.pdf, April 24, 2012.

U.S. Department of Commerce, Census Bureau, Current Population Survey (CPS), October 1967 through October 2009. http://nces.ed.gov/programs/digest/d10/tables/dt10 115.asp Table 115, downloaded October 21, 2011.

Valentine G. (2003) Boundary crossings: Transitions from childhood to adulthood. Children's Geographies, 1, 3752.

World Factbook (2011) Country comparison: distribution of family income, Gini index. https://www.cia.gov/library/publications/the-world-factbook/rankorder/2172rank.html, accessed March 24, 2011.

Zucker RA, Fitzgerald HE and Moses HD. eds. (1995) Emergence of alcohol problems and the several alcoholisms: A developmental perspective on etiologic theory and life course trajectory. In D Cicchetti and DJ Cohen. eds. Developmental psychopathology, Vol. 2: Risk, Disorder, and Adaptation. Pp. 677-711. John Wiley and Sons, New York.

\footnotetext{
Endnote

'More detailed information about the MTF design and methods is available in Johnston et al (2011a) and at www.monitoringthefuture.org
} 